\title{
A VEZ E A VOZ DAS CRIANÇAS: PROTAGONISMO NA DINÂMICA DAS PRÁTICAS PEDAGÓGICAS?
}

\author{
Eliana Maria Ferreira (iD) e Cindy Romualdo Souza Gomes iD2
}

\section{Resumo}

Este artigo apresenta reflexões de um estudo que tem como objetivo analisar os conflitos e os aspectos de resistência dos docentes quando se deparam com normatizações referentes ao trabalho pedagógico ao compreender as crianças como centro da prática educativa. Para a coleta de dados, debruçamos sobre as situações cotidianas narradas pelas professoras nos momentos de formações, realizadas nos encontros mensais de estudos, lançando mão da teoria de Norbert Elias $(1994 ;$ 2006) olhando as relações de poder entre as crianças e as professoras, observando gatilhos que desequilibram o poder ora para o adulto ora para a criança em uma relação de instabilidade e conflitos de interesses. Os resultados indicam que o protagonismo das crianças se restringe apenas nas práticas pedagógicas quando suas professoras vão planejar o que irão desenvolver com elas e que não percebem que estão à margem dos processos de construção das aprendizagens, das relações interpessoais, ocupações dos espaços, organização da rotina e do tempo na instituição. Analisando as narrativas das professoras, percebemos que nos entremeios do cotidiano, nos detalhes das relações do dia a dia o que prevalece de fato, são as opiniões, ritmos e interesses não só da professora, mas dos demais adultos da instituição. Disso compreendemos que não basta contemplar no papel os interesses da criança, é preciso um olhar refinado e vigilante sobre a prática, sobre as relações que priorizem o exercício por parte dos pequenos de sua independência e protagonismo na construção das aprendizagens, das relações com o outro e com o meio.

Palavras-chave: Educação infantil; Relações de poder; Formação docente.

\section{THE CHILDREN'S TURN AND VOICE: DO THEY HAVE A PROTAGONISM IN THE DYNAMICS OF PEDAGOGICAL PRACTICES?}

\section{Abstract}

This article presents reflections of a study that aims to analyze the conflicts and resistance aspects of teachers when they are faced with norms related to pedagogical work when understanding children as the center of educational

\footnotetext{
${ }^{1}$ Doutora e Mestre em Educação pela Universidade Federal da Grande Dourados (UFGD). Graduada em pedagogia. É Coordenadora Pedagógica da E.M. Frei Eucário Schimitt SEMED/Dourados/MS. Membro do Grupo de Estudos e Pesquisas em Educação Infantil de Dourados - GEINFAN / MS.

${ }^{2}$ Graduação em Pedagogia e Mestrado em Educação (UFGD/2011). É membro do Grupo de Pesquisa Educação e Processo Civilizador. Atualmente é Coordenadora Pedagógica do Centro de Educação Infantil Municipal (CEIM) Helena Efigênia Pereira. Dourados / MS.
} 
practice. For data collection, we focused on the daily situations narrated by the teachers in the moments of training, held in the monthly study meetings, making use of Norbert Elias' theory $(1994 ;$ 2006) looking at the power relations between children and teachers, observing stimuli that unbalance power, sometimes for the adult, sometimes for the child, in a relationship of instability and conflicts of interest. The results indicate that the protagonism of children is restricted only to pedagogical practices when their teachers will plan what they will develop with them and that they do not realize that they are outside the processes of learning construction, interpersonal relationships, occupation of spaces, organization of the routine and time in the institution. Analyzing the teachers' narratives, we realized that in the midst of daily life, in the details of everyday relationships, what actually prevails are the opinions, rhythms and interests not only of the teacher, but of other adults in the institution. Thus, we understand that it is not enough to contemplate the child's interests on paper, it is necessary to take a careful look at the practice, on the relationships that prioritize the exercise by children of their independence and protagonism in the construction of learning, relationships with others and with the social environment.

Keywords: Early childhood education; Power relations; Teacher training.

\section{Introdução}

A escrita deste texto, intitulado a vez e a voz das crianças, protagonismo na dinâmica das práticas pedagógicas, surge da experiência de três educadores, ao constituir o núcleo de educação infantil da secretaria municipal de educação de Dourados/MS (SEMED), no primeiro semestre de 2017. Este artigo pode ser entendido como um relato de experiência seguido de análises críticas sobre os fenômenos encontrados entre professoras ${ }^{1}$, da rede municipal, nos momentos de formação continuada.

Esses momentos eram organizados em polos por proximidade geográfica reunindo cerca de duas a três instituições. Sendo assim falávamos com cerca de trinta a sessenta profissionais, que durante nossos encontros mensais com duração de duas horas nos rederam estudos e trocas de experiências, sobretudo, para discussões propondo o protagonismo das crianças e das próprias professoras na dinâmica de suas práticas pedagógicas.

Neste sentindo, nosso objetivo é refletir sobre os conflitos e os aspectos de resistência dos docentes quando se deparam com crescentes normatizações referentes ao trabalho pedagógico ao compreender as crianças como centro da prática educativa, ou seja, isso implica significar a criança e considerá-la de maneira integral na instituição como indivíduo que frequenta aquele espaço e interfere nele com ações, ideias, materiais e construções tanto quanto os adultos.

${ }^{1}$ Será utilizado professoras pois a rede municipal de Dourados é constituída por um grande número de mulheres professoras.

Perspectivas em Diálogo, Naviraí, v. 08, n. 17, p. 286-301, maio/ago. 2021. 
Para tanto iremos nos debruçar sobre as situações cotidianas narradas pelas professoras e por nós, lançando mão da teoria de Norbert Elias (1994; 2006), olhando as relações de poder entre as crianças e as professoras, observando gatilhos que desequilibram o poder ora para o adulto ora para a criança em uma constante relação de instabilidade e conflitos de interesses.

A grosso modo os adultos envolvidos, no funcionamento da instituição educacional para atendimento das crianças, deveriam balizar suas atividades/funções a partir das necessidades, ritmos e interesses das crianças e suas diferentes faixas etária. Evitando praticar o que se tem atualmente que é a busca por garantir a ordem a partir de rotinas rígidas e uniformes (MACHADO; SARAT; FERREIRA, 2012) com o intuito de moldar posturas e normatizar os comportamentos dos pequenos.

Durante nossas reuniões de orientações sobre a organização do trabalho pedagógico, notamos que de maneira unânime, as profissionais diziam nortear suas práticas com planejamentos semanais ou quinzenais, ou ainda com projetos, todos estruturados a partir de momentos de observação e escuta quanto aos interesses, dúvidas ou temas recorrentes entre as crianças de suas turmas.

Essa postura das professoras realmente aponta o considerar as crianças enquanto centro do planejamento, porém a participação delas fica limitada a apenas esses momentos. Conforme os estudos, nas formações continuadas, avançaram para questões cotidianas, relação interpessoal professora/criança, criança/criança, o que imperava nas narrativas durante as trocas de experiências vinculavam-se a sistematização do tempo, organização do espaço e condução da turma em atividades, tudo pensado pela professora ou com interferência das demais funcionárias da instituição, tais como as cozinheiras, coordenadora, faxineiras etc., que articulavam suas necessidades de tempo e desempenho de funções sobre os ritmos das crianças.

Frente as determinações do que cada funcionário da instituição deve desempenhar para seu funcionamento e atendimento aos pequenos, cabe perguntar qual é a função das crianças na instituição. Instituição essa construída para atendê-las de maneira integral, e aqui cabe ressaltar que nosso discurso não versa em se fazer tudo o que as crianças querem, mas conduzir as aprendizagens e cotidiano de modo a contemplar seus interesses na instituição.

Classificada como categoria geracional, a infância e a criança, ainda são percebidas como desimportantes e, apesar de sua completude, é muito comum, a partir de um repertório adulto, ouvirmos expressões ${ }^{1}$ como: "não seja criança!", "você está sendo infantil!", "você parece criança!". Vemos reverberar nesse discurso um comportamento adultocêntrico ${ }^{2}$, herdado ao longo da história, e que até o presente momento se propaga quando estigmatiza a criança

\footnotetext{
${ }^{1}$ Para além das expressões, vemos ações indicativas que a criança ainda não é respeitada na nossa sociedade.

${ }^{2}$ Refere-se a fazeres e entendimentos vinculados apenas ao adulto e para o adulto, sendo este detentor da palavra final, ou seja, tendo razão.
} 
ou aquilo que ela produz e que é, por vezes, considerado como desimportante, incompleto, sem sentido e respeitabilidade.

Diante destas discussões, é importante destacar as Diretrizes Curriculares Nacionais para a Educação Infantil - DCNEI (2010) que contribui com as proposições sobre a criança enquanto "sujeito histórico e de direitos que, nas interações, relações e práticas cotidianas que vivencia, constrói sua identidade pessoal e coletiva, sobre a natureza e a sociedade, produzindo cultura". (BRASIL, 2010. p. 12)1. Assimilar e praticar essa representação de criança, outorgada pela Lei, dá-nos a sensação de que todas as crianças têm os seus direitos garantidos, e automaticamente, como num passe de mágica, passarão a ser auscutada. ${ }^{2}$

Auscutada não apenas quando se precisa estruturar um planejamento ou projeto pedagógico, auscutada quando em uma proposta de atividade a turma muda seu interesse ao encontrar dentro da sala uma borboleta e surgem muitos assuntos e hipóteses sobre o inseto, é mudar, flexibilizar e compartilhar os rumos de cada dia. Garantindo que as ações diárias girem ao redor dos interesses das crianças. É uma caminhada diária de mãos dadas crianças e professora e não um cabo de guerra entre o que a professora precisa fazer e o que a criança não quer fazer

As crianças não devem ir à instituição e serem servidas de atenção, cuidados e ensinamentos. Marcando assim, o entendimento de que elas sejam "tabulas rasas", "espojas" ou "folhas em branco" que absorvem/recebem e vão embora. As crianças devem participar, interferir e construir o convívio, os cuidados e as aprendizagens naquele lugar.

\section{Visibilidade e protagonismo dos pequenos}

As pesquisas realizadas atualmente, nos campos da sociologia da infância e os estudos da infância, tratam as crianças enquanto atores sociais plenos. Tais perspectivas têm buscado desconstruir a infância sob uma perspectiva adultocêntrica, na qual prevalece a visão de infância permeada pela inocência, de um vir a ser (o que você quer ser quando crescer?), em termos de conhecimento para participar da vida social.

Pode-se dizer que os modos de se pensar o que é ser criança e a relevância da infância, é uma ideia da idade moderna. Entretanto, temos que ter o cuidado

\footnotetext{
${ }^{1}$ Não podemos deixar de citar documentos essenciais que contribuíram para a origem das DCNEI: a Constituição Federal de 1988, Art. 208, que legitimou como direito da criança pequena à educação em creches e pré-escolas; O Estatuto da Criança e do Adolescente - ECA, em 1990; e a publicação da Lei de Diretrizes e Bases - LDB 9.394/96, que regulamenta no Art. 29 o direito à educação infantil.

${ }^{2}$ As discussões de Rocha (2008) revelam que é necessária uma ampliação dos termos ouvir ou escutar que equacionam no termo auscutar, ou seja, compreender a comunicação feita pela criança levando em consideração que a maneira de receber e perceber a escuta dela perpassará pelo crivo de interpretação do adulto.
} 
ao relacionar tal sentimento com as instituições que foram criadas exclusivamente em função do trabalho feminino (KUHLMANN, 1998).

Dessa forma, o aparecimento das instituições como as salas de asilo, creches e pré-escolas, surgidas após a criação das escolas, é fruto das mudanças econômicas, políticas e sociais que ocorreram na sociedade. Entre elas, o trabalho da mulher fora do lar, em decorrência de uma nova organização familiar.

Em meio a esse panorama, "criaram-se leis e propagaram-se instituições sociais na área da saúde pública, do direito e da família, das relações de trabalho, da educação" (KUHLMANN 1998). Portanto, a intervenção do governo nas concepções assistenciais à infância abandonada e da filantropia, iniciativa não governamental, as influências médicas higienistas e dos psicólogos foram fatores que contribuíram para a equalização abstrata de uma 'natureza infantil' e que, de certa forma, traçava o destino social das crianças, "[...] transformando em sujeitos úteis, numa sociedade desejada, que era definida por poucos". (BUJES, 2001, p. 15).

Não podemos deixar de destacar que o "ser criança" modifica-se de sociedade em sociedade e dentro da mesma sociedade, em tempos e espaços diferentes. Não podemos refutar que as crianças sempre existiram, por isso fazem parte de uma categoria estrutural permanente que nunca desaparece ainda que seus membros mudem de maneira contínua e seus conceitos variem historicamente (CORSARO, 2011). Segundo Elias (1994),

A sociedade, como sabemos, somos todos nós; é uma porção de pessoas juntas. Mas uma porção de pessoas juntas na India e na China formam um tipo de sociedade diferente da encontrada na América ou na Grã-Bretanha; a sociedade composta por muitas pessoas individuais na Europa do século XII era diferente da encontrada nos séculos XVI ou XX (ELIAS, 1994, p. 9).

Consideramos esclarecer que, o conceito de sociedade levará em conta indivíduos adultos e crianças. O que implica refletir na constituição da formação desses sistemas de interações, com posições de poder e papéis, oriundos no interior das diferentes sociedades.

Vejamos, as relações estabelecidas com as crianças e adultos em uma instituição educativa, não é a mesma que ela estabelece com a sua família, e não será a mesma com o grupo, por exemplo, do parque, de uma festa de aniversário, ou de uma igreja, ou seja, as "figurações" nas relações entre adultos e crianças se estabelecem de inúmeras formas. Esses diferentes lugares de interação entre crianças e crianças e crianças com adultos e a construções de relações são chamadas por Elias (2006) de figurações,

[...] apenas os seres humanos formam figurações uns com os outros, $[. .$.$] os seres humanos, em virtude de sua interdependência$ fundamental uns dos outros, agrupam-se sempre na forma de figurações específicas[...] essas figurações não são fixadas nem 
com relação ao gênero humano, nem biologicamente [...]. Essas figurações possuem peculiaridades estruturais e são representantes de uma ordem de tipo particular [...] um ser humano singular pode possuir uma liberdade de ação que lhe permita desligar-se de determinada figuração e introduzir-se em outra (ELIAS, 2006 p. 25-27).

Norbert Elias (1994, p. 19) considera que " a relação entre a parte e o todo é uma certa forma de relacionamento, nada mais, e como tal, sem dúvida já é bastante problemática". O autor não distingue a parte do todo, como também não separa indivíduo e sociedade.

Para ele, as sociedades não têm uma forma perceptível. Consideradas com totalidades são sempre mais ou menos incompletas, em um fluxo contínuo, com mudanças mais rápidas ou mais lentas das formas vivas. As pessoas estão em um movimento mais ou menos perceptível, vão e vêm como lhe apraz, faz parte de determinados lugares, com funções distintas e está presa a certos rituais e as formas específicas de comportamento. E assim também é uma instituição de educação infantil.

As relações sociais são tecidas em meio às pluralidades que se alternam e oscilam "entre a orientação social do esforço individual e as possibilidades sociais de consumá-lo" (ELIAS, 1994, p. 101).

Semelhantemente, Lahire (2013) nos alerta que, ao observar o mundo social à escala individual, tomamos rapidamente consciência do fato de que as "influências" socializadoras que modelam os indivíduos estão longe de serem perfeitamente coerentes, ou seja, os indivíduos raramente possuem patrimônios de disposições homogêneas e não se transferem sistematicamente de uma situação à outra. (2013, p. 17). Na perspectiva de Elias (1994),

Só pode haver uma visão comunitária mais livre de perturbações e tensões se todos os indivíduos dentro dela gozarem de satisfação suficiente; e só pode haver uma existência individual mais satisfatória se a estrutura social pertinente forma mais livre de tensão, perturbação e conflito. A dificuldade parece estar em que, nas ordens sociais que se nos apresentam, uma das duas coisas sempre leva a pior. Entre as necessidades e inclinações pessoais e as exigências da vida social, parece haver sempre, nas sociedades que nos são familiares, um conflito considerável, um abismo quase instransponível para a maioria das pessoas implicadas. (ELIAS, 1994, p. 15).

Lahire (2015) e Elias (1994) pontuam que a vida em sociedade é modelada e oscila por meio de conflitos, ou seja, nasce em meio a um emaranhado de divergências que ora pendem para o lado das inclinações pessoais, ora para as exigências da vida social, como em uma balança.

Outra questão levantada por Lahire trata sobre a "ideia de construção social da realidade [que] permite ressituar a história na percepção das coisas e dizer que a realidade é o produto da história". (LAHIRE, 2015, p. 296). Negar 
esta máxima é afirmar a inexistência "de diferentes períodos da vida humana, por parte dos adultos, assim como as atribuições e representações relacionadas às características específicas de cada um deles [...]". (KUHLMANN e FERNANDES, 2004, p. 16).

Ao compartilhar da ideia de construção social da realidade estamos pensando também nas crianças e suas infâncias, em um indivíduo pequeno, que é processo/produto da história construída pela ótica da invisibilidade ${ }^{1}$.

Entretanto, o problema é que a construção da realidade social não é apenas simbólica, ela também é material, está em objetos, instituições, textos, existem "coisas" que não são simplesmente realidades simbólicas. "[...] Existem coisas que restringem a ação dos atores, que são externas a eles e das quais eles nem sempre têm consciência" (LAHIRE, 2015, p. 296-297).

Ou seja, não reconstruímos a realidade a todo momento, ela é decorrente das grandes estruturas, dos objetos, das instituições e que se impõe aos indivíduos. Quando levamos a crer com a ideia de construção social que, se isso se constrói, então se desconstrói facilmente, e que se constrói diariamente como efeito da intencionalidade dos atores, nos enganamos completamente.

Diante deste contraponto há que pesar que "a construção histórica da infância foi o resultado de um processo complexo de produção de representações sobre as crianças, de estruturação dos seus quotidianos e mundos de vida e, especialmente, de constituição de organizações sociais para as crianças" (SARMENTO, 2004, p. 11).

Não podemos refutar a ideia de que a infância está na dependência da espécie geracional instaurada pelos adultos para a manutenção da vida dos seus integrantes, o que gera para estes últimos uma relação assimétrica do poder que tem os adultos e as crianças. (FERREIRA, 2016). O poder do controle dos adultos sobre elas é legitimado e reconhecido, o que não ocorre de forma contrária. Assim, diante da geração adulta, a infância é colocada numa posição de inferioridade. (SARMENTO, 2005). Elias (1980) destaca que as crianças também possuem poder em relação aos adultos, que foram sendo conquistadas a partir das mudanças nas sociedades, principalmente nas relações entre pais e mães para com suas filhas e filhos.

Nessa perspectiva, consideramos que a relativa autonomia das crianças, apontada por Elias, pode ser produto de uma história socialmente construída. Nas palavras dele, "deve-se descobrir que elas não são simplesmente adultos pequenos. Elas vão se tornando adultas, individualmente, por meio de um processo social civilizador que varia segundo o estado de desenvolvimento dos respectivos modelos sociais de civilização". (ELIAS, 2012, p. 469). Ou seja, trata-se de uma história fundada em "relações de poder, dependência e

${ }^{1}$ Sarmento (2007) em seu estudo sobre a infância sustenta que o processo de ocultação é decorrente das concepções marginais, periféricas produzidas historicamente sobre as crianças e das maneiras como elas foram inscritas em imagens sociais. 
interdependência [...] presentes no cotidiano [e nas estruturas], constantemente, em um processo de transformação" (FERREIRA; SARAT, 2013, p. 90).

O conceito de relativa autonomia em Elias (2012) pode ser entendido como o produto ou a produção de algo construído necessariamente de forma interdependente com outros indivíduos nas relações humanas durante toda a vida.

As crianças não são simplesmente adultos pequenos, elas possuem autonomia, mesmo que relativas se comparadas com as dos adultos atualmente, mas isso nem sempre foi assim. Esse processo de perceber as crianças e as relações entre pais/mães e filhos/as foi um longo processo construída com características que visavam condicionar comportamentos normativos socialmente.

Para Elias essa relação e detenção do poder vincula-se a quem retém ou monopoliza "[...] aquilo que outros necessitam, como por exemplo, comida, amor, segurança, conhecimento, etc. Portanto, quanto maior as necessidades desses últimos, maior é a proporção de poder que detêm os primeiros". (ELIAS, 1994 p. 53).

\section{Entre expectativas e realidades: dinâmicas entre crianças e professoras}

Sobre o modo como se olha, escuta e interage com as crianças nas instituições temos alguns exemplos que surgiram nos estudos de formação continuada, muitas narrativas foram feitas pelas professoras participantes e outras foram introduzidas por nós para ampliarmos as discussões sobre protagonismo infantil.

Certa vez em um momento de formação o tema central era sobre rotinas, falávamos sobre algumas práticas que são repetidas sem explicações plausíveis que agreguem valor às aprendizagens das crianças. A discussão era sobre a formação da fila. Filas são necessárias? Nós adultos gostamos de fazer fila ou estar em filas? $\mathrm{E}$ por que as crianças têm que enfrentá-las? Existem filas que são imprescindíveis por conta de esperar a vez para fazer algo, mas filas de deslocamento, será que são necessárias?

A conversa seguiu sobre as filas e seus determinismos: formação de duas filas a de meninas e de meninos, os mais baixos na frente e os altos atrás, quem é pequeno sempre vai na frente e tem a alegria de segurar a mão da professora, quem é alto sempre fica por último, e quem fica no meio é empurrado, puxado, tem os calcanhares pisoteados e os sapatos arrancados e muitas vezes nem enxergam para onde estão indo. Além das disputas entre empurrões e puxões para ver quem vai na frente até a professora chegar e a organizar por ordem de tamanho.

Sobre essa prática argumentamos: As filas demoram minutos para serem feitas e duram segundos no trajeto que fazem. Existem filas que cantam. Cantam a mesma música e pedimos para que as professoras calculassem, 
quantas vezes por dia as crianças formam filas e cantam a mesma música e o quanto isso dava de idas e vindas e de repetições durante os 200 dias letivos. Além, é claro, de considerarem os mencionados determinismos das filas, principalmente as de deslocamento. Pois as de ordem, compreendermos serem importantes, ainda que se possa pensar em outros modos de se organizar as crianças e os afazeres. Ainda assim, com toda essa descrição sobre a fila, uma professora disse:

[...] a fila é para manter a ordem, se eu atravessar o pátio com crianças andando de costas ou fazendo isso que você está sugerindo e que faz com suas crianças (pular de um pé só, andar com as mãos nos joelhos, fingir que são ninjas e assim se deslocarem da sala para o refeitório), a minha coordenadora vai olhar e pensar que eu não tenho controle de sala! (Professora Valda, grifos nossos, 03/2017).

Frente ao dito, notamos que a professora não considera o que é agradável ou importante para as crianças, um desafio motor, a modificação de uma rotina, refletir sobre algo que é repetido ano após ano, são práticas menores do que o medo de ser julgada pelo o outro. Suas atitudes e escolhas enquanto professora são norteadas a partir do que ela supõe que seja importante para o outro a seu respeito, assim se distancia da criança enquanto centro do planejamento. Para Gomes e Santos (2012),

Diante da relação ambiente e comportamento, podemos então afirmar que nossas posturas frente a determinadas situações seguem a lógica de causa e consequência, pois prevemos que na ausência de uma atitude dita civilizada, sofreríamos consequências que poderiam findar em danos pessoais imediatos. A reprovação de um comportamento geraria exposição à vergonha, ao ridículo (GOMES; SANTOS, 2012, p. 47).

Por parte das professoras, elas mesmas se caracterizaram e cercearam como devem desempenhar seus papéis na instituição, principalmente nas relações interpessoais entre professoras e crianças, professoras e coordenação, e professoras e familiares das crianças. Neste sentido compreendem que são ainda detentoras do conhecimento, da ordem e da disciplina versus a tendência do protagonismo da criança na instituição de educação infantil. Em seus discursos e opiniões sobre esse protagonismo expressam compreende-lo como fraqueza profissional, bagunça, mimo às crianças e sobre a posição/papel/poder a quem manda na instituição e tem capacitação e bom senso para fazê-lo.

De um modo geral, as professoras estão acostumadas a exercerem suas práticas 'autoritárias, cristalizadas, mecânicas, desvinculadas dos saberes das crianças e que legitimam a antecipação de formas e conteúdo do ensino fundamental. (SANTOS, 2016).

Diante dessas considerações questionamos: É possível mudar essa perspectiva paradigmática de educação centrada na professora sem banalizar a relação de poder entre adultos e crianças, e colocar em xeque seu controle e (c) (1) 
poder neste cenário da instituição, sem questionar sua capacidade de cuidar e educar crianças pequenas? As professoras estão mais preocupadas com o modo que a família e os próprios colegas de trabalho poderão perceber a sua atuação frente às crianças? Até quando as professoras interpretarão que possibilitar a participação das crianças durante o todo do cotidiano na instituição não diminui seu papel?

Seguimos refletindo sobre mais um momento de conversa com as professoras, nós provocamos trazendo a seguinte narrativa: em um dado dia foi apresentada às crianças de Pré 1 (entre 4 e 5 anos de idade) uma atividade a qual uma criança não queria fazer, logo a mesma começou a conversar com as demais crianças da turma, argumentando contra a proposta da professora propondo que fizessem outra coisa. Esse movimento de organização entre as crianças foi chamado de maneira carinhosa e irônica como sendo a organização de um "motim de crianças" que logo expressaram o que queriam fazer.

Neste ponto da conversa foi observada, entre o grupo de professoras envolvidas nos estudos de formação continuada, a inteligência das crianças bem como suas idades, na articulação em se organizarem e reconhecerem a importância de uma opinião em grupo, o peso da maioria sobre a minoria que era a professora. A professora, por sua vez, não só ouviu a turma em suas vontades como também as atendeu, e em outro momento deu continuidade à atividade.

Em meio a posturas de concordância e de até risos surpresos sobre a perspicaz do grupo de crianças, uma professora interrompeu e disse: "mas esse motim é um desrespeito à professora! ". E começou a relatar o caso de seu filho em outra escola (ensino fundamental) que na situação estava apertado para ir ao banheiro, porém a professora de sua turma tinha determinado horário para as crianças sentirem sede e vontade de fazer xixi.

Enfim ela narrou que seu filho já apertado para ir ao banheiro, e sabendo das regras, simplesmente se levantou e foi ao banheiro sem pedir à professora, pois já sabia que receberia um não seguido de explicações sobre horários de organização das necessidades fisiológicas da turma, mas que em sua condição já não poderia esperar mais e nem ouvir as regras. Dito em nossa discussão a professora concluiu que seu filho foi desrespeitoso com a professora de sua turma e que merecia ser punido e ficar sem intervalo. E no caso das crianças de Pré, ela não admitiria tal comportamento da turma e que iria sim dar continuidade a proposta de atividade.

Vejamos, se a construção ou a mudança na estruturação de relacionamento entre professora e crianças é estabelecida de maneira horizontal, com partilha de interesses e ideias, de atendimentos de pedidos ainda que não imediatamente, de reciprocidade e cumplicidade não há como interpretar o expressar de uma vontade como sendo desrespeitosa. E entre isso e aquilo que se quer e se deve fazer há um tempo em que tudo se encaixa e todos são contemplados.

As crianças entre paredes, muros e cercas das instituições de educação infantil, têm seus modos de subverter a ordem dos interesses dos adultos sobre (c) (1)

Perspectivas em Diálogo, Naviraí, v. 08, n. 17, p. 286-301, maio/ago. 2021. 
os seus. Como exemplo, segue mais uma descrição dos nossos encontros de formação continuada, quando falávamos justamente sobre a sensibilidade que a professora deve ter com os interesses da turma, que muitas vezes, por mais que o planejamento seja considerando as crianças, há dias em que a turma está com suas energias voltadas para outros aspectos da instituição.

Dentre tantas situações cotidianas, abordamos o dia do brinquedo, os familiares das crianças chegavam e questionavam, "professora pode trazer brinquedo?" E então tinham como resposta "ah, sim eu vou ver que dia é melhor e eu mando um bilhete avisando", depois de estudos sobre essa prática, já não era demarcado um dia específico e ficava livre para que a criança levasse quando quisesse. Pois, em meio as atividades da turma, a professora iria administrar o brinquedo trazido de casa e suas possibilidades de brincadeiras.

Neste contexto as crianças do maternal 2, traziam brinquedos em dias variados, em uma tarde conversando surgiu o assunto de brinquedos de rodinhas. Uma das meninas teve a ideia de marcar para todos trazerem no dia seguinte seus brinquedos para juntos brincarem. Assim ela fez. Cada familiar que chegava para buscar uma criança da turma ela abordava na porta e explicava sobre o dia do brinquedo sugerindo trazer 'motoquinha', bicicleta, patinete ou skate. Os familiares riam, ouviam e olhavam para a professora que acenava discretamente com a cabeça confirmando que poderiam seguir com o pedido da pequena.

Por fim, o dia da brincadeira sobre rodinhas tinha chegado, todos da turma levaram seus brinquedos, porém a pequena idealizadora do evento se esqueceu de levar o seu, e foi um início de tarde com muita frustação. Diante disso, a professora entendeu que essa necessidade e interesse do grupo precisava ser formalizado por meio de bilhete para os familiares da turma evitando assim o esquecimento e demarcando a participação das crianças na organização de uma atividade para elas.

Essa narrativa ocorreu com uma de nós, e serviu de exemplo durante nossas formações de como possibilitar o protagonismo das crianças no dia a dia. Não estamos dizendo, que frente as crianças seremos permissivas a tudo que quiserem, estamos pontuando que é possível, é negociável e ocorre com o consentimento de todos.

Nessa perspectiva, a sociologia da infância pode contribuir nas discussões teórico-metodológicas e no equilíbrio que buscamos numa balança de poder. Assim, temos uma perspectiva apresentada por Sarmento e feita por Willian Corsaro, sociólogo americano, que nos oferecem orientações acerca da sua tese de reprodução interpretativa.

Conceito que pode ser associado ao de 'estruturação' [...] e que exprime a ideia de que as crianças, na sua interação com os adultos, recebem continuamente estímulos para a integração social, sob a forma de crenças, valores, conhecimentos, disposições e pautas de conduta, que ao invés de serem passivamente incorporados em saberes, comportamentos e atitudes, são transformados, gerando juízos, interpretações e 
condutas infantis que contribuem para configuração e transformação das formas sociais. Deste modo, não são apenas os adultos que intervêm junto das crianças, mas as crianças também intervêm junto dos adultos. As crianças não recebem apenas uma cultura constituída que lhes atribui um lugar e papéis sociais, mas operam transformações nessa cultura, seja sob a forma como a interpretam e integram, seja nos efeitos que nela produzem, a partir das suas próprias práticas. (SARMENTO, 2009, p. 9).

A despeito da citação acima, temos crianças e adultos enquanto promotoras e receptoras de estímulos e aprendizagens o que gera para as primeiras - as crianças - uma apreensão criativa daquilo que elas se apropriam, resultando em novos significados.

Os estudos da infância, notadamente avançam e reconhecem as crianças enquanto sujeito principais. Nesta mesma direção, temos os/as docentes da educação infantil que se constitui e constrói seu perfil processualmente e em virtude da criança e das suas infâncias nas sociedades, o que pressupõe a necessidade de professor/as. Nesse sentido, os indivíduos estabelecem entre si relações de interdependência, nas distintas figurações que se formam e se transformam no cotidiano. E esse processo de transformação se constitui historicamente nas relações de poder, dependência e independência dos grupos sociais geracionais.

Estamos construindo formas diferentes e criativas de olhar para a criança hoje no sentido de ouvi-las, o que resulta em novas fontes, novos objetos e instrumentos metodológicos complexos. Entretanto, questiona-se em que medida as pesquisas com crianças contribuem na formação do professor de educação infantil.

A infância enquanto categoria social é dependente de cuidados que é indispensável à sua sobrevivência. Nessa relação de dependência por parte das crianças, legitimamos o poder dos adultos. Para tanto, existe "uma rede de relações entre seres humanos, onde a balança de poder muda constantemente, de forma assimétrica, sem dicotomizar autores e atores, indivíduo e sociedade" (GEBARA, 2005, p.2),

Assim as relações de interdependência entre adultos e crianças desenvolvidas durante as ações de cuidado e educação são relações imbuídas de aspectos que levam o adulto a conhecer o desenvolvimento humano, mais especificamente o desenvolvimento infantil. Tais conhecimentos são fundamentais e não seria possível se não houvesse a necessidade ou a dependência por parte da criança. Ou seja, "o desenvolvimento do conhecimento humano ocorre sempre no interior das configurações vividas, sendo um aspecto fundamental do desenvolvimento destas pessoas em sociedade". (GEBARA, 2005, p.2-3)

E disto, dos dois caminhos, ainda assim, ambos se tornam conflitivos, no vertical, no qual a professora manda e as crianças obedecem, sempre haverá uma ou mais crianças que de algum modo tentarão subverter a ordem e serão opositoras ao que está sendo dito para fazer ou não fazer. Já na construção do (c) (1) $(3)$ 
relacionamento horizontal será construído uma cumplicidade com a qual as crianças cada vez mais exporão a professora suas vontades e do mesmo modo buscarão muitas vezes sobrepor suas necessidades ainda que sejam insensatas testando os limites de tal relacionamento.

\section{Considerações finais}

Demos início a essa discussão querendo responder ao título 'sobre a vez e voz do protagonismo das crianças na dinâmica das práticas pedagógicas' pois notamos em nossas experiências de trabalho e pesquisas que as crianças apenas são consideradas nas práticas pedagógicas quando suas professoras vão planejar o que irão desenvolver com elas.

Quando as professoras precisam dar conta da parte burocrática e organizacional do trabalho pedagógico elas recorrem aos interesses de suas turmas e sistematizam a partir disso ações que contemplem temas recorrentes, curiosidades e interesses coletivos dos pequenos, buscando assim, garantir aprendizagens significativas. Porém, neste entremeio os processos de construção dessas aprendizagens têm ficado fadado ao controle, ritmo, organização, preferencias e necessidades das professoras e demais adultos das instituições de educação infantil.

Em hipótese, esse exercício de planejar visando o interesse das turmas, ocorre, pois, o município não possui um material didático a ser seguido, o que avaliamos como sendo adequado e uma oportunidade ímpar. Disto compreendemos que sem mais a fazer, as professoras internalizaram que é da criança que parte o caminho a ser seguido ao logo do ano, premissa essa que reconhecemos também como adequada e garantida nos documentos que regularizam essa etapa da educação.

Infelizmente o protagonismo das crianças se restringe apenas a esse momento de escrita. Por isso, as professoras respondem que suas crianças são sim o centro de seus planejamentos, mas elas próprias não percebem que as crianças estão a margem dos processos de construção das aprendizagens, das relações interpessoais, ocupações dos espaços, organização da rotina e do tempo na instituição.

Analisando cuidadosamente as narrativas das professoras, percebemos que nos entremeios do cotidiano, nos detalhes das relações do dia a dia o que prevalece de fato, são as opiniões, ritmos e interesses não só da professora, mas dos demais adultos da instituição.

Disso compreendemos que não basta contemplar no papel os interesses da criança, é preciso um olhar refinado e vigilante sobre a prática, sobre as relações que priorizem o exercício por parte dos pequenos de sua autonomia, independência e protagonismo na construção das aprendizagens, das relações com o outro e com o meio. Não basta trazer uma proposta para fazer algo, é preciso questionar como podemos fazer, quando faremos, que cor usaremos, aonde colocaremos. 
Pensando sobre as relações de poder de Norbert Elias (1994), observamos a existência de uma tensão de força por parte dos adultos sobre as crianças, e ainda assim_observamos que essas tensões também pendem para outras relações entre os adultos em uma figuração de hierarquia e clientelismo.

Ou seja, a professora exerce seu poder enquanto detentora de conhecimento e pessoa responsável por um grupo de crianças, deste modo seu ritmo, opiniões e interesses prevalecem, porém ainda assim o que ela faz está subordinado a relação de poder que a coordenadora possui sobre seu trabalho, que por sua vez, está subordinado muitas vezes às opiniões dos pais das crianças, e esta relação subordina-se a questões políticas, que não iremos nos deter.

Como próprio Elias diz, o poder está com quem detém conhecimento, e muitas vezes a ausência de argumentação cientifica por parte da professora e coordenação fazem com que sejam subordinadas aos seus clientes os pais das crianças. Disso percebemos também como a mobilidade das relações se sobrepõem e influenciam no fazer pedagógico de profissionais inseguras com sua formação.

Nessas relações e configurações de poder as crianças em suas diferentes linguagens e possibilidades buscam subverter a ordem e expressar e reivindicar suas necessidades e interesses.

Enfim neste ponto respondemos a nossa pergunta inicial, pois a professora e os demais adultos que convivem com os pequenos nas instituições que souberem equilibrar e dividir esse poder de decisão, escolha, tempo, preferencias e aprendizagens conseguirá possibilitar o protagonismo dos pequenos.

Neste exercício de análise e escrita chegamos a reflexões pertinentes a nossas práticas, o protagonismo das crianças apenas será possível quando o poder entre a relação professora e criança for partilhado em um convívio de cumplicidade de interesses, trocas e cooperação.

Será que o incomodo de partilhar as decisões de uma parceria entre professora e crianças no caminhar das atividades pedagógicas é tão grande a ponto de impossibilitar essa construção de relacionamento horizontal onde exista a cumplicidade entre adultos e crianças.

\section{REFERÊNCIAS}

BRASIL. Ministério da Educação e do Desporto. Secretaria de Educação Fundamental. Diretrizes curriculares nacionais para a educação infantil. MEC, 2009.

BUJES, Maria Isabel Edelweiss. Escola Infantil: pra que te quero. CRAIDY, Maria; KAECHER, Gládis Elise P. da. (Orgs.) In: Educação Infantil pra que te quero. Porto Alegre: Artmed, 2001, p. 13-22. 
CORSARO, Willian. A. Métodos etnográficos no estudo da cultura de pares e transição iniciais na vida das crianças. In: MULLER, Fernanda; CARVALHO, Ana Maria Almeida (Orgs.). Teoria e prática na pesquisa com crianças. São Paulo: Cortez, 2009, p. 83-103.

CORSARO, Willian. Sociologia da Infância. Tradução Lia Gabriele Regius Reis. Porto Alegre: Artmed, 2011.

ELIAS, Norbert. A sociedade dos indivíduos / Norbert Elias; organizado por Michael Schoter, tradução, Vera Ribeiro; revisão técnica e notas, Renato Janine Ribeiro. Rio de Janeiro: Jorge Zahar Ed., 1994.

ELIAS, Norbert. Escritos e Ensaios; 1: Estado, processo, opinião pública/ Norbert Elias; organização e apresentação, Federico Neiburg e Leopoldo Waisbort; tradução texto em inglês, Sergio Benevides; textos em alemão, Antonio Carlos dos Santos; textos em holandês, João Carlos Pijnappel. Rio de Janeiro: Jorge Zahar Ed., 2006

ELIAS, N. A civilização dos pais. Tradução a partir do espanhol para o português, feita por Bruno Gontyjo do Couto e com supervisão de Edson Farias. Revista Sociedade e Estado - v. 27, n. 3, p. 469-493, set./dez, 2012.

FERREIRA, Eliana Maria; SARAT, Magda. 'Civilizar a infância': relações entre adultos e crianças no espaço pedagógico da educação infantil. Rev. Poiésis Pedagógica, Catalão-GO, v. 11, n. 1, p. 86 -106, jan/jun. 2013.

GOMES, Cindy Romualdo Souza; SANTOS, Reinaldo dos. Inserções sociais: família, escola e internet. In: Sobre processos civilizadores: diálogos com Norbert Elias. SARAT Magda; SANTOS Reinaldo dos (Org.). - Dourados: Ed. UFGD, 2012, p.45-65.

KUHLMANN, Moysés Jr. Infância e educação infantil: uma abordagem histórica. Porto Alegre: Mediação, 1998.

KUHLMANN, Moysés Jr.; FERNANDES, Rogério. Sobre a história da infância. In: FARIA FILHO, Luciana Mendes. (Org.). A Infância e sua Educação: materiais, práticas e representações (Portugal e Brasil). Belo Horizonte: Autêntica, 2004, p. 13-26.

LAHIRE, Bernad. O singular plural. Cadernos do Sociofilo. Rio de Janeiro, v. 3, n. 4, p.16-26, 2013. Disponível em: http://sociofilo.iesp.uerj.br/wpcontent/uploads/2013/12/2_Lahire.pdf. Acesso em 15 jun. 2016.

LAHIRE, Bernad. Entrevista: Bernard Lahire. Sociologias, Porto Alegre, v. 17, n. 38, p. 280-302, jan./abr. 2015. Disponível em: 
http://www.scielo.br/scielo.php?script=sci_arttext\&pid=S151745222015000100280 . Acesso em: 15 jun. 2016.

MACHADO, Daniele de Matos; SARAT, Magda; FERREIRA, Eliana Maria. "Combinados, comportamento e regras de convivência": o processo de civilidade para crianças da educação infantil. In. XIV Simpósio Internacional Processos Civilizadores: Civilidade, Fronteira e Diversidade. IV Seminário do Grupo de Pesquisa, Educação e Processo Civilizador. 2014, Londrina. Anais Eletrônicos... Londrina, 2014, p. 17-29. Disponível: http://www.uel.br/grupoestudo/processoscivilizadores/portugues/sitesanais/anais14/arquivos/textos/Po ster/Resumos_Expandidos/Daniele_Machado.pdf Acesso em 18 jan. 2018.

SANTOS, Maria Walburda dos. Formação de professoras para Educação Infantil. Entrevista com Maria Walburga dos Santos (UFSCAR). Disponível: http://www.anped.org.br/news/formacao-de-professoras-para-educacaoinfantil-entrevista-com-maria-walburga-dos-santos-ufscar. Acesso em: 15 jan. 2018.

SARAT, Magda. A infância e a formação civilizada do indivíduo em Norbert Elias. In. XIV Simpósio Internacional Processos Civilizadores: Civilidade, Fronteira e Diversidade. IV Seminário do Grupo de Pesquisa, Educação e Processo Civilizador. 2014, Londrina. Anais Eletrônicos... Londrina, 2014, p. 7-27. Disponível: http://www.uel.br/grupoestudo/processoscivilizadores/portugues/sitesanais/anais14/arquivos/textos/M esa_Coordenada/Trabalhos_Completos/Magda_Sarat.pdf. Acesso. 15 jan. 2018.

SARMENTO, Manuel Jacinto. As culturas da infância nas encruzilhadas da $\mathbf{2}^{\mathbf{a}}$ modernidade. Braga: Instituto de Estudos da Criança, Universidade do Minho, 2004. Retirado do site:

http://proferlaotrabalhosalunos.pbworks.com/f/AS+CULTURAS+DA+INFANCIA +NA+ENCRUZILHADA+DA+SEGUNDA+MODERNIDADE..pdf. Acesso em $15 \mathrm{de}$ abril de 2017.

SARMENTO, Manuel Jacinto. Gerações e alteridade: interrogações a partir da sociologia da infância. Educ. Soc. Campinas, v. 26, n. 91, p.361-378, maio/ago, 2005.

Recebido em: 26 de fevereiro de 2021. Aceito em: 02 de abril de 2021. Publicado em: 30 de junho de 2021. 